\title{
High salinity enhances the adsorption of $17 a$-ethinyl estradiol by polyethersulfone membrane: isotherm modelling and molecular simulation
}

\author{
J.Y. Goh ${ }^{1} \cdot$ K. S. Goh ${ }^{1} \cdot$ Y. M. Yip ${ }^{2} \cdot$ C. K. $\mathrm{Ng}^{3,4}$ (I)
}

Received: 28 May 2020 / Revised: 2 June 2021 / Accepted: 9 June 2021 / Published online: 21 June 2021

(c) The Author(s) 2021

\begin{abstract}
The increasing occurrence of steroidal hormone micropollutant in the aquatic environment and their associated consequences have caused serious environmental concerns globally. Adsorptive removal of hormonal pollutants using polymeric membranes has been suggested but information on their performance in various environmental conditions is lacking. In this study, we examined the effect of salinity on the performance of polyethersulfone (PES) membrane to remove synthetic hormone $17 \alpha$-ethinyl estradiol (EE2) from water. Our results show that an increase of salinity from 0 to $3 \%$ results in higher retention of EE2 onto PES membrane from 79.3 to $98.7 \%$. The experimental results fit the Freundlich isotherm model better as compared to the Langmuir model. The Freundlich parameters $n$ and $K_{\mathrm{f}}$ yielded the highest values at $3 \%$ salinity. The molecular simulation results suggest that a high salinity increases the binding energy between EE2 and PES membranes, promoting the PES-EE2 interaction through $\pi-\pi$ interaction, hydrogen bonding and hydrophobic interaction. This study provides valuable information for improving design of specialised treatment facilities (in farming, pharmaceutical industries, etc.) to allow better removal of EE2 and other low-polar organic contaminants from water via a membrane-based sorption-elution method, and we recommend the inclusion of salinity as a factor in modelling the adsorption capacity of membranes to prevent the oversaturation of membrane and minimise the release of contaminants into the environment.
\end{abstract}

Keywords $17 \alpha$-ethinyl estradiol $\cdot$ Polyethersulfone $\cdot$ Salinity $\cdot$ Molecular simulation $\cdot$ Adsorption

\section{Introduction}

Endocrine-disrupting chemicals (EDCs) are a group of emerging contaminants that are potentially hazardous towards living organisms even at trace concentrations (Gmurek et al. 2017; Rodríguez-Gómez et al. 2017). Due to

Editorial responsibility: Josef Trögl.

C. K. Ng

ng0009at@e.ntu.edu.sg

1 School of Civil and Environmental Engineering, Nanyang Technological University, Singapore 639798, Singapore

2 School of Physical and Mathematical Sciences, Nanyang Technological University, Singapore 637371, Singapore

3 Singapore Centre for Environmental Life Sciences Engineering, Interdisciplinary Graduate School, Nanyang Technological University, Singapore 637551, Singapore

4 Department of Engineering Science, University of Oxford, Parks Road, Oxford OX1 3PJ, UK their widespread use in chemical and agricultural industries, EDCs are ubiquitous in the aquatic environment (Solé and Matamoros 2016). Among these EDCs, steroidal estrogens can affect the reproductive health of wildlife and human population (Silva et al. 2012). Unlike other naturally occurring hormones such as estrone (E1), estradiol (E2) and estriol (E3), $17 \alpha$-ethinyl estradiol (EE2) is a synthetic hormone that is persistent in the natural environment (Ma et al. 2018). As a result, EE2 has caught worldwide attention as countries are concerned over their ubiquity and elevated concentrations in water bodies (Aris et al. 2014; De Rudder 2004). A well-documented effect caused by EE2 is the alteration of reproductive physiology and morphology of fishes (Sumpter 2010). Till date, many research has revealed EE2 as agents capable of causing feminisation of male fishes at concentrations as low as 1-4 ng/L (Aris et al. 2014; Sumpter 2010). The widespread of intersex fish have already been reported near treatment plants in the USA, Canada, across Europe and Japan (Wise et al. 2011). 
Presently, activated sludge (AS) is the principal technological process to treat wastewater (Ren et al. 2007). Through AS treatment, biological degradation and adsorption to suspended solids followed by removal, are two pathways to eliminate estrogens from influent (Silva et al. 2012; Andersen et al. 2005). As hormones tend to have low solubility (Nagpal and Meays 2016), low Henry's constant, low biodegradability, hydrophobic and recalcitrant in nature, adsorption onto AS is theorised to be the main removal mechanism of estrogens especially at low sludge retention time (SRT) (Ren et al. 2007; Rovani et al. 2014). However, the AS process tends to only partially remove recalcitrant chemicals as it is not designed to remove synthetic hormone (Lyko et al. 2005; Matamoros et al. 2016). Furthermore, EE2 is resistant to biodegradation (Aris et al. 2014). As such, the AS process is inadequate to efficiently remove steroidal estrogens from wastewater (Fernandes et al. 2011). Although concentrations of EE2 can be alleviated through modification of conventional wastewater treatment plants, these upgrades were deterred by huge economic costs (McKie 2016; Ávila et al. 2015). Therefore, there is a need to develop a cleaner, economical and effective alternative approach to remove estrogenic micropollutants from the aquatic environment.

Adsorptive removal of EE2 using polymeric membranes has been suggested to be a feasible and sustainable solution (Schäfer et al. 2011). Previous study showed that PES membranes provide high adsorption capacities for low-polar organic solvents ( $\mathrm{Ng}$ and Cao 2015), and they are postulated to provide an effective adsorbent for the hydrophobic EE2. By adopting the concept of sorption-elution cycle, it is possible for effective removal of trace concentrations of estrogens where it can be remediated via chemical or biological treatment (Ng et al. 2017; Bope et al. 2018). To develop this idea, there is a need to obtain more information on the interaction mechanism between EE2 and PES membrane and how environmental parameters like salinity affects the performance of membrane on EE2 removal. Therefore, the objective of this research is to evaluate the adsorption capability of PES on EE2 under different saline environments via experimental isotherm studies as well as molecular simulation modelling. With this information, we can better understand the mechanism of contaminant-absorbent interaction and optimise the adsorption process to optimise the removal of emerging contaminants such as endocrine-disrupting chemicals from the environment.

This study started in 2016 at the Nanyang Technological University, Singapore.

\section{Materials and methods}

\section{Materials, chemicals and reagents}

EE2 (CAS number: 57-63-6) and all chemical used in this study were purchased from Sigma-Aldrich (Singapore) unless otherwise stated. Stock solutions of EE2 (1 g/L) were dissolved in ethanol (HPLC grade) and stored at $-20{ }^{\circ} \mathrm{C}$ for further use. Syringe filters housing a hydrophilic polyethersulfone (PES) membrane with an effective filtration area of $2.8 \mathrm{~cm}^{2}$ and pore size of $0.2 \mu \mathrm{m}$ (Acrodisc Syringe Filters with Supor Membrane, Pall Corporation) were used throughout this study.

\section{Analytical methods}

\section{Quantification of hormone concentrations}

Quantification of hormone concentrations were performed with modification as previously described (Ng et al. 2017). Prominence HPLC system (Shimadzu, Singapore) with SPD-20A UV-Vis Detectors was used for the analysis of samples and an 18 -C $5 \mu \mathrm{m} 10 \mathrm{~cm} \times 2.1 \mathrm{~mm}$ column (Ascentis, Washington, USA) for separation. The mobile phase was prepared by mixing $40 \%(\mathrm{v} / \mathrm{v})$ acetonitrile (ACN) (HPLC grade) and spiked with $6.9 \mathrm{mM}$ of acetic acid and topped up with Milli-Q water. Elmasonic S120H degasser was set to high power mode, at $40{ }^{\circ} \mathrm{C}$ for $20 \mathrm{~min}$ and this setting was used as a pre-treatment to remove any gas or air bubbles in the mobile phase. Analytical software "LabSolutions" was used to set the HPLC operating condition to an oven temperature of $40{ }^{\circ} \mathrm{C}$ while the LC stop time was adjusted to $10 \mathrm{~min}$ per run for each sample. The pump was set to isocratic flow at $0.5 \mathrm{ml} / \mathrm{min}$ and the volume of sample injected into the HPLC for analysis was set to $10 \mu \mathrm{L}$. The column was conditioned with the mobile phase for $4 \mathrm{~h}$ at a flow rate of $0.5 \mathrm{ml} / \mathrm{min}$ prior to the analysis of the data. The wavelength at which the estrogenic hormone peaked was at $200 \mathrm{~nm}$. The elution time for EE2 was determined as 3.48 min under these conditions.

\section{EE2 retention experiment}

$5 \mathrm{ml}$ of $10 \mathrm{mg} / \mathrm{L}$ EE2 solutions with salt concentrations of $0 \%, 0.9 \%$ and $3 \%$ were filtered through the PES membrane using Masterflex 1/S digital pump system at a rate of $0.1 \mathrm{ml} / \mathrm{s}$. Filtrates and initial solutions of the dead-end membrane filtration were collected and analysed by HPLC (Ng et al. 2017). 


\section{Adsorption isotherms modelling}

Predetermined volume of solutions containing $5 \mathrm{mg} / \mathrm{L}$ EE2 (corresponding to $20,40 \ldots 200 \mu \mathrm{g}$ of EE2) at various salinities (i.e. $0 \%, 0.9 \%$ and $3 \%$ ) were filtered through the PES filters using Masterflex 1/S digital pump system at a rate of $0.1 \mathrm{ml} / \mathrm{s}$. Filtrates and initial solutions of the dead-end membrane filtration were collected and analysed by HPLC ( $\mathrm{Ng}$ et al. 2017).

The results obtained from the batch sorption experiments were used to determine sorption parameters. Several isotherm equations are available in the literature; two widely used adsorption models were selected for this study: Langmuir and Freundlich isotherms (Crittenden et al. 2012; Chung et al. 2015).

The Langmuir (site-limited) sorption isotherm is an empirical isotherm model assuming that adsorption can only occur at a finite number of localised sites, and the adsorbed layer is one molecule thick (monolayer adsorption) (Chen 2015). It defines the equilibrium between the concentrations of a compound in the aqueous and on the solid phase (Schwarzenbach et al. 2005). This relationship is shown in Eq. (1).

$\frac{1}{q_{\mathrm{e}}}=\frac{1}{Q_{\mathrm{m}}}+\left(\frac{1}{C_{\mathrm{e}}}\right)\left(\frac{1}{Q_{\mathrm{m}} b}\right)$

where $q_{\mathrm{e}}$ is the adsorbate adsorbed to the adsorbent ( $\left.\mathrm{mg} / \mathrm{g}\right)$; $Q_{\mathrm{m}}$ is the maximum adsorption capacity $(\mathrm{mg} / \mathrm{g}) ; b$ is the Langmuir's constant and $C_{\mathrm{e}}$ refers to the equilibrium concentration of the substrate $(\mathrm{mg} / \mathrm{L})$. If the Langmuir parameter "b" does not deviate from the literature, $Q_{\mathrm{m}}$ will then be determined from a series of adsorption experiment with known masses.

Apart from Langmuir Isotherm, the Freundlich isotherm was developed as an empirical model for prediction of adsorption behaviour. It assumes multiple types of sorption sites acting in parallel, with different sorption energy for each site (Schwarzenbach et al. 2005). This relationship is shown in Eq. (2) in a linearised form and Eq. (3) in nonlinearised form (Chung et al. 2015; Valix et al. 2004).

$\ln q_{\mathrm{e}}=n \ln C_{\mathrm{e}}+K_{\mathrm{f}}$

$q_{\mathrm{e}}=K_{\mathrm{f}} C_{\mathrm{e}}^{n}$

where $q_{\mathrm{e}}$ and $C_{\mathrm{e}}$ follow the same definition of Langmuir Isotherm, except $K_{\mathrm{f}}$ which represents Freundlich constant and $n$ represents the Freundlich exponent (Chung et al. 2015) which measure the adsorption capacity and intensity respectively (Chen 2015; Schwarzenbach et al. 2005).

\section{Molecular simulation}

The atomistic models of the monomer unit PES and the hormone EE2 were constructed. The atomic structures were constructed using Accelrys Material Studio version 2016. The initial structures were optimised by DFT calculations using $\mathrm{Dmol}^{3}$ in order to generate stable conformations. The DFT calculations used the gradient-corrected functional (GGA) and PW91 with the DNP basis set (Perdrew and Wang 1992). The atomic charges for the structures were parameterised according to the AM1-BCC charge model (Jakalian et al. 2002) using Antechamber (Wang et al. 2006).

After the DFT optimisation, molecular dynamics (MD) simulations were carried out for each solvated solute molecule in various aqueous $\mathrm{NaCl}$ concentrations. All MD simulations were conducted with the AMBER package, version 10.0 (Pearlman et al. 1995; Case et al. 2005) with the FF99SB force field (Hornak et al. 2006). To build the simulation system, the complex structure (PES-EE2) was placed in a truncated octahedron box, solvated with TIP3P water (Berendsen et al. 1981).

For each simulation system, energy minimisation was performed to relax the structure using the conjugate gradient algorithm (Zimmermann 1991), followed by the steepest descent algorithm (Debye 1909). Prior to the equilibration molecular dynamics simulation, 100 ps NVT MD simulation in the absence of any restraint was performed to heat up the simulation system. The simulation temperature was increased from 0 to $300 \mathrm{~K}$ using Langevin dynamics (Uberuaga et al. 2004). After heating up the system, $20 \mathrm{~ns}$ NPT equilibration MD simulations of the various $\mathrm{NaCl}$ concentrations were performed.

All simulations' integration time step was set to $2 \mathrm{fs}$, and all short-range non-bonded interactions were modelled using Lennard Jones potentials with a cut-off at $1.2 \mathrm{~nm}$. The long-range electrostatic interactions were calculated using the particle mesh Ewald (PME) algorithm (Darden et al. 1993; Essmann et al. 1995) and the SHAKE algorithm (Ryckaert et al. 1977) was used to constrain all bond lengths involving hydrogen atoms.

The equilibrated trajectory files were post-processed and analysed using PTRAJ (Roe and Cheatham 2013) and the intermolecular interactions were calculated with the following criteria (Sinnokrot and Sherrill 2004):

\begin{tabular}{ll}
\hline $\begin{array}{l}\text { Type of intermolecular interac- } \\
\text { tion }\end{array}$ & Cut-off criteria \\
\hline$\pi-\pi$ (Sandwich) & $3.70 \AA$ \\
$\pi-\pi$ (T-shaped) & $5.00 \AA$ \\
$\pi-\pi$ (Parallel-displaced) & $3.75 \AA$ \\
\hline
\end{tabular}


Type of intermolecular interac- Cut-off criteria tion

\begin{tabular}{ll}
\hline Hydrogen bond & $\begin{array}{r}3.40 \AA \text { between heavy atoms } \\
\text { and } 135^{\circ} \text { angle cut-off for the } \\
X-H \ldots \ldots Y \text { atom triple }\end{array}$ \\
\hline
\end{tabular}

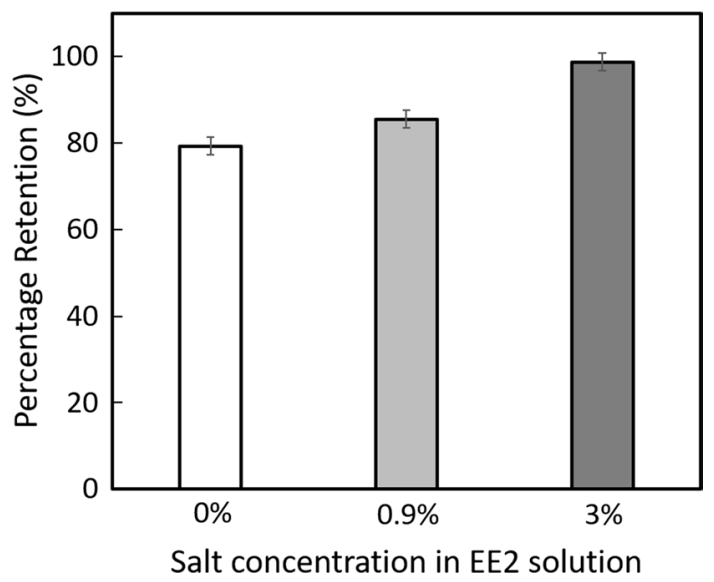

Fig. 1 Percentage retention of EE2 of PES membrane by passing feed volume of $5 \mathrm{ml}$ at $10 \mathrm{mg} / \mathrm{L}$ of EE2 with salt concentrations of $0 \%$, $0.9 \%$ and $3 \%$. All experiments were done in triplicates $(n=3)$
Type of intermolecular interac- Cut-off criteria tion

Hydrophobic $5.00 \AA$

\section{Results and discussion}

\section{Effects of salinity on EE2 removal efficiency and adsorption capacity of PES membrane}

For the effective removal of hormone contaminants, i.e. EE2, from the environment, it is important to understand the performance of the membrane under different salinity conditions in the environment. Three salinity points were chosen in this study: $0 \%, 0.9 \%$ and 3\%, which corresponds to fresh, brackish and seawater, respectively. Our results showed that increasing salinity from 0 to 0.9 to $3 \%$ increases the retention efficiency of EE2 by the PES filter from 79.3 to $98.7 \%$ (Fig. 1). This suggests that the interactions between PES and EE2 are influenced by different ionic strengths generated from the various salt concentrations.

To further investigate the role of salinity in the adsorption process of EE2, batch adsorption tests were conducted. Figure 2 shows the effect of salinity $(0 \%, 0.9 \%$ and $3 \%)$ on the removal of EE2 by PES membrane at an accumulated mass of EE2 during dead-end membrane filtration. The maximum adsorption capacity of EE2 by the PES filter can be observed to be at $49 \mu \mathrm{g}(\sim 3.50 \mathrm{mg} / \mathrm{g}$ membrane $)$ for $0 \%$ salinity and $60 \mu \mathrm{g}(\sim 4.29 \mathrm{mg} / \mathrm{g}$ membrane $)$ for $3 \%$ salinity. This means that the change in salinity has a direct effect on the EE2 adsorption capacity of PES membranes. On the other hand, with a low EE2 content in the solution (i.e. 20
Fig. 2 Effects of salinity at $0 \%, 0.9 \%$ and $3 \%$ salinity on adsorption of EE2 onto PES membrane via dead-end membrane filtration of $5 \mathrm{mg} / \mathrm{L} \mathrm{EE} 2$ solution

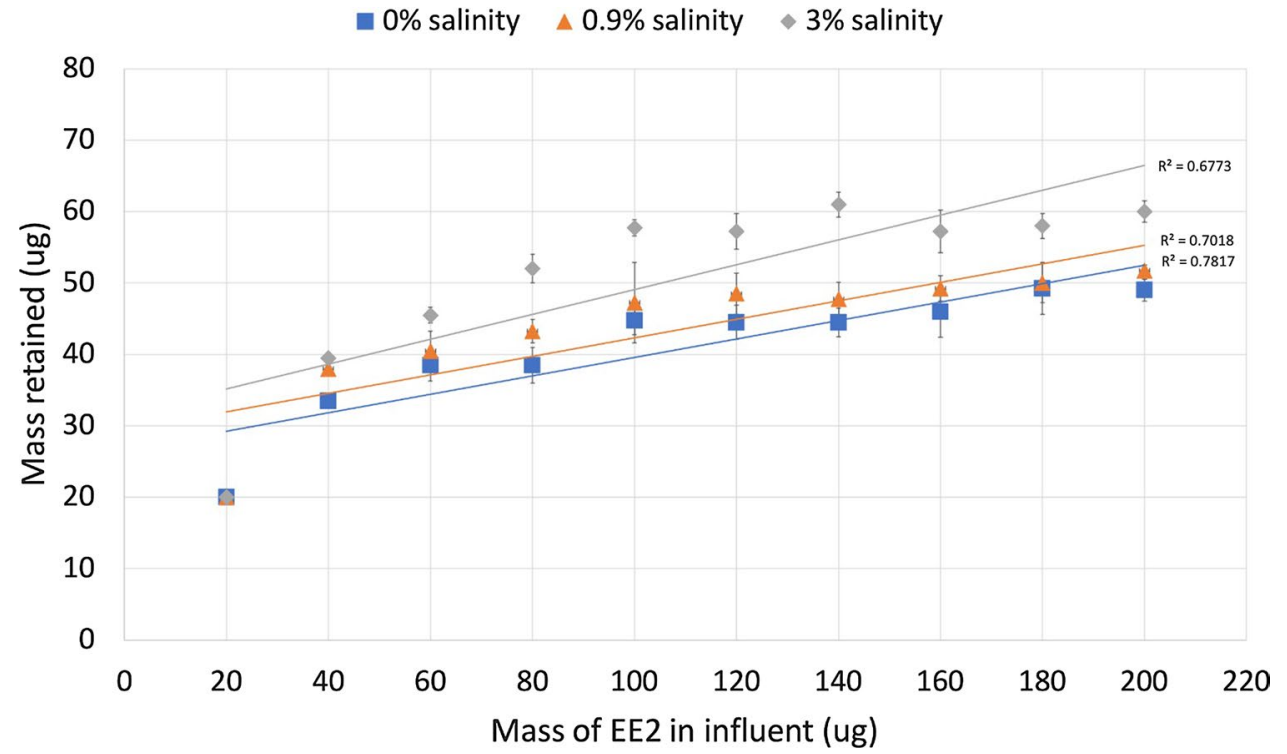


Table 1 Physicochemical properties of EE2

\begin{tabular}{lllll}
\hline $\begin{array}{l}17 \alpha \text {-Ethinyl } \\
\text { estradiol, EE2 }\end{array}$ & $\begin{array}{l}\text { Max projection } \\
\text { diameter }(\mathrm{nm})\end{array}$ & $\begin{array}{l}\text { Sorption con- } \\
\text { stant, } K_{\mathrm{oc}}\end{array}$ & Log $K_{\text {ow }}$ & $\mathrm{pKa}$ \\
& $1.46^{\mathrm{a}}$ & $4770^{\mathrm{b}}$ & $4.15^{\mathrm{c}}$ & $10.46^{\mathrm{d}}$ \\
\hline
\end{tabular}

${ }^{\mathrm{a}}$ Han et al. (2013a)

${ }^{\mathrm{b}}$ Silva et al. (2012)

${ }^{\mathrm{c}}$ Aris et al. (2014)

${ }^{\mathrm{d}}$ Ivashechkin et al. 2004)

$\mu \mathrm{m}$ or less), the filtration efficiency is close to $100 \%$ and seems independent of the $\mathrm{NaCl}$ concentration in contrast to higher values of the EE2 content in the solution (Fig. 2). This shows that the EE2 adsorption efficiency of membranes near saturation are more susceptible to changes in salinity than those of unsaturated membranes. Our study suggests that, at low membrane saturations, membrane-based wastewater treatment is effective in continuously removing low levels of EE2 (1.2-259 ng/L) commonly seen in municipal wastewater treatment plants (Chimchirian et al. 2007). However, when the membranes are more saturated, their actual capacity may be much lower than their predicted capacity when salinity of the wastewater falls below normal condition, e.g. during heavy rainfall or monsoon season. As such, our study suggests the inclusion of salinity as a factor in modelling the adsorption capacity of membranes to prevent oversaturation of membrane and minimise the release of EE2 into the environment.

Since the nominal pore size of the PES membrane of $0.2 \mu \mathrm{m}$ is larger than the molecular size of EE2 of $1.46 \mathrm{~nm}$ by two-threefold (Table 1), the underlying mechanism for the removal of EE2 by filtration is not via size exclusion (Han et al. 2013a). Based on the structure of the PES and $\mathrm{EE} 2$, it is theoretically possible that there is anion- $\pi$ interaction between the benzene ring of the PES and a deprotonated alcohol group in EE2. However, due to the high $\mathrm{pKa}$ (Ivashechkin et al. 2004; Tomšíková et al. 2012) of EE2 and the neutral $\mathrm{pH}$ range $(\sim \mathrm{pH} 7)$ of the media prepared in the experiments, a negligible amount of EE2 will dissociate to form anions. This suggests that the anion- $\pi$ interaction is not one of the main contributing factors for the adsorption process between EE2 and PES membrane.

Previous studies had suggested that the main mechanism for the removal of micropollutants such as hormone by microfiltration is largely due to physical adsorption onto the membrane surfaces (Schäfer et al. 2011; Han et al. 2012). In a study on nanofiltration removal of estrone, the increase in hydrophobicity of the membrane resulted in a higher adsorption rate of the hormone (Hu et al. 2007). A study had shown that the increase in ionic strength of a solution will encourage hydrophobic interactions in general (Hsu and Huang 2002). In a solution of higher ionic strength, water molecules interact more with the ions from salt as compared to polar groups on EE2 and PES, possibly leading to an increased in reversible binding between EE2 and PES to achieve a more stable configuration. It is also possible that the increase in ionic strength of a solution due to the increase in salt concentration promotes $\pi-\pi$ interactions between the aromatic and phenolic groups of EE2 and PES membrane. This is in line with our experimental results where the adsorption of EE2 on the hydrophobic surface of the PES membrane is significantly affected by salinity which influences the ionic strength of the feed solution, hence influences the binding

Table 2 Adsorption isotherm parameters determined from experimental data

\begin{tabular}{|c|c|c|c|}
\hline \multicolumn{4}{|c|}{ Adsorption isotherm at $0 \%$ salinity } \\
\hline \multicolumn{2}{|c|}{ Langmuir isotherm } & \multicolumn{2}{|c|}{ Freundlich isotherm } \\
\hline$Q_{\mathrm{m}}$ & $4.26( \pm 0.21) \mathrm{mg} / \mathrm{g}$ & $K_{\mathrm{f}}$ & $1.84( \pm 0.06) \mathrm{mg} / \mathrm{g}$ \\
\hline$b$ & $0.49( \pm 0.05) \mathrm{L} / \mathrm{mg}$ & $n$ & $3.29( \pm 0.11) \mathrm{L} / \mathrm{mg}$ \\
\hline$R^{2}$ & 0.71 & $R^{2}$ & 0.76 \\
\hline \multicolumn{4}{|c|}{ Adsorption isotherm at $0.9 \%$ salinity } \\
\hline \multicolumn{2}{|c|}{ Langmuir isotherm } & \multicolumn{2}{|c|}{ Freundlich isotherm } \\
\hline$Q_{\mathrm{m}}$ & $4.50( \pm 0.14) \mathrm{mg} / \mathrm{g}$ & $K_{\mathrm{f}}$ & $2.05( \pm 0.15) \mathrm{mg} / \mathrm{g}$ \\
\hline$b$ & $0.53( \pm 0.05) \mathrm{L} / \mathrm{mg}$ & $n$ & $3.55( \pm 0.16) \mathrm{L} / \mathrm{mg}$ \\
\hline$R^{2}$ & 0.93 & $R^{2}$ & 0.93 \\
\hline \multicolumn{4}{|c|}{ Adsorption isotherm at $3 \%$ salinity } \\
\hline \multicolumn{2}{|c|}{ Langmuir isotherm } & \multicolumn{2}{|c|}{ Freundlich isotherm } \\
\hline$Q_{\mathrm{m}}$ & $5.12( \pm 0.28) \mathrm{mg} / \mathrm{g}$ & $K_{\mathrm{f}}$ & $2.77( \pm 0.09) \mathrm{mg} / \mathrm{g}$ \\
\hline$b$ & $0.76( \pm 0.08) \mathrm{L} / \mathrm{mg}$ & $n$ & $4.35( \pm 0.22) \mathrm{L} / \mathrm{mg}$ \\
\hline$R^{2}$ & 0.89 & $R^{2}$ & 0.81 \\
\hline
\end{tabular}



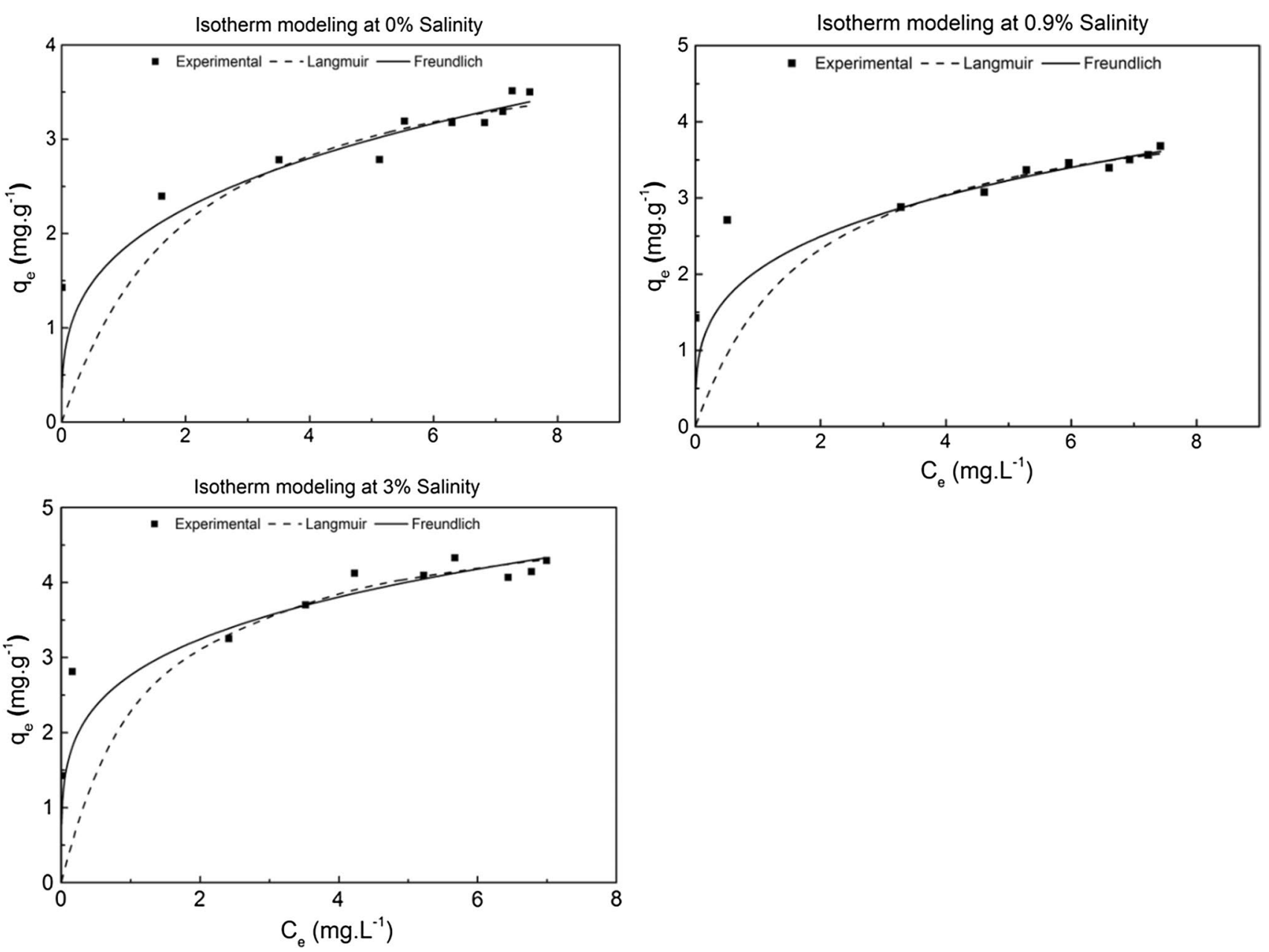

Fig. 3 Adsorption isotherms of EE2 on PES membrane and comparison of isotherm models of Langmuir and Freundlich at $0 \%, 0.9 \%$ and $3 \%$ salinity

affinity between PES and EE2. This shows that the salinity of feed solution can strongly affect the PES membrane retention efficiency and adsorption capacity of EE2 at near membrane saturation, which is an important factor to consider in the design of a membrane-based treatment facilities.

\section{Adsorption isotherm}

Modelling the experimental isotherm data is an essential way of predicting the mechanism of adsorption (Chen 2015). Experimental data from the tests of EE2 adsorption onto the PES membrane at $0 \%, 0.9 \%$ and $3 \%$ salinity were fitted to the linear forms of isotherm to obtain the isotherm parameters shown in Table 2. The values of the determination coefficients obtained from the models were used as fitting criteria to identify these isotherms. Langmuir and Freundlich isotherms profiles for EE2 onto PES membrane under different salinity conditions are shown in Fig. 3. Although there were slight discrepancies between the predicted and experimental values, the prediction of mass adsorbed by the PES membrane can be reasonably determined using the models at higher equilibrium concentrations. Considering the $\mathrm{R}^{2}$ values for both models, Freundlich model gave better fitting than Langmuir model for $0 \%(0.760>0.707)$ and $0.9 \%$ salinity $(0.934>0.930)$ except for $3 \%$ where the $\mathrm{R}^{2}$ value is smaller $(0.811<0.891)$. However, with reference to the graphical analysis in Fig. 3, it can be observed that the model that best fit the experimental data was the Freundlich model as Freundlich model provides better prediction even at lower $C_{\mathrm{e}}$ for $0 \%, 0.9 \%$ and $3 \%$ salinity. Therefore, the results indicate that the Freundlich model, rather than the Langmuir model, provided a better prediction tool for adsorbate removal efficiency and a mathematical model to describe the adsorption equilibrium.

Interestingly, the $n$ and $K_{\mathrm{f}}$ values derived from the Freundlich model also coincides with the relationship established between salinity and binding affinity between PES and EE2. According to the previous literature (Giles et al. 
1960), the analysis of the term $\mathrm{n}$ of Freundlich equation is a measure of favourability of adsorption; when $n$ is greater than 1 , the adsorption is favourable and higher the $n$ value, the more favourable the adsorption (Delle Site 2001). Since the sorption curve presents a concave shape and the values of $n$ for adsorption of EE2 onto PES equal to 3.29, 3.55 and 4.35 at $0 \%, 0.9 \%$ and $3 \%$ salinity, respectively, the process is favourable (Crittenden et al. 2012) (Table 2). By further comparison of the n values, the $n$ value corresponding to $3 \%$ salinity is the highest, followed by $0.9 \%$, and $0 \%$ salinity. This shows that the higher the salinity, the more favourable is the adsorption process, which further supports our previous finding that higher salinity promotes adsorption between EE2 and PES.

Analysing the value of $K_{\mathrm{f}}$ of the Freundlich isotherm which is an indicator of adsorption capacity (Schwarzenbach et al. 2005; Febrianto et al. 2009), the value of $K_{\mathrm{f}}$ is $1.84,2.05$ and 2.77 at $0 \%, 0.9 \%$ and $3 \%$ salinity, respectively (Table 2), where the $K_{\mathrm{f}}$ value at $3 \%$ salinity is the highest. This indicates that the capacity of the PES membrane to bind onto EE2 at 3\% salinity is greater than that of $0.9 \%$ and $0 \%$ salinity, further validating the relationship between salinity and adsorption of EE2. Even though there were discrepancies between experimental and the predicted values for some instances, the Freundlich isotherm gives a holistic and reasonable adsorption model for the adsorption of EE2 onto PES membrane between $0 \%, 0.9 \%$ and $3 \%$ salinities. The comparison of the Freundlich parameters at different salinities further affirms the suitability of Freundlich isotherm to model the adsorption of EE2 onto PES membrane in this study. It may be worthwhile to test the data set with Liu isotherm (Machado et al. 2011) in future studies, but is out of the scope of this study.

\section{Molecular simulation}

It is theoretically possible that PES and EE2 undergo chemical interactions (e.g. covalent bonding) under the influence of UV radiation or free radical substitution. However, such occurrences are few and far between, and out of the scope of (a)

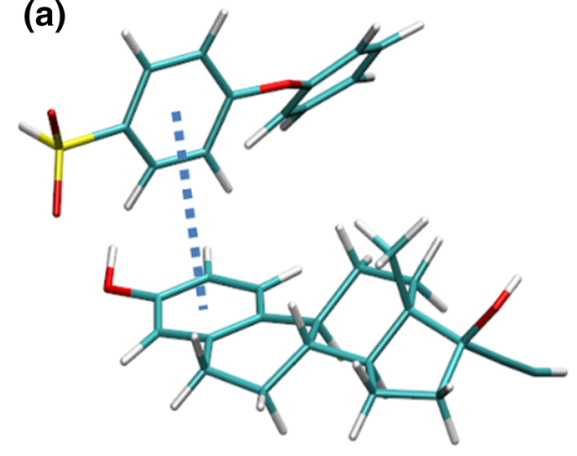

(b)

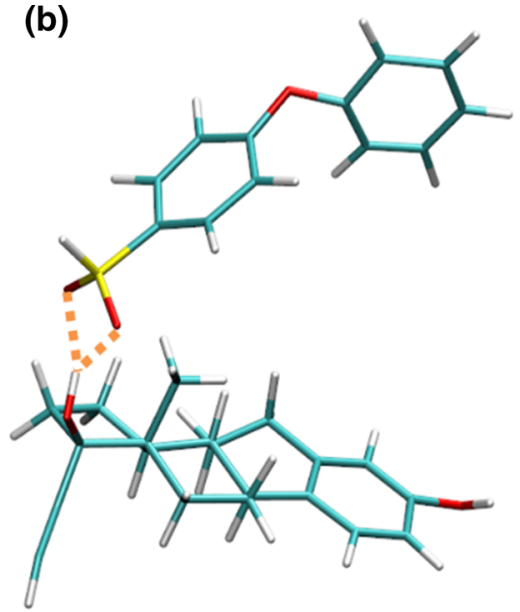

(c)

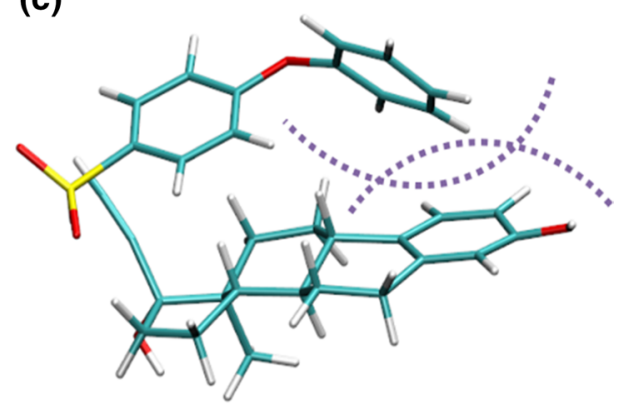

(d) Types of Intermolecular Interactions between PES and EE2

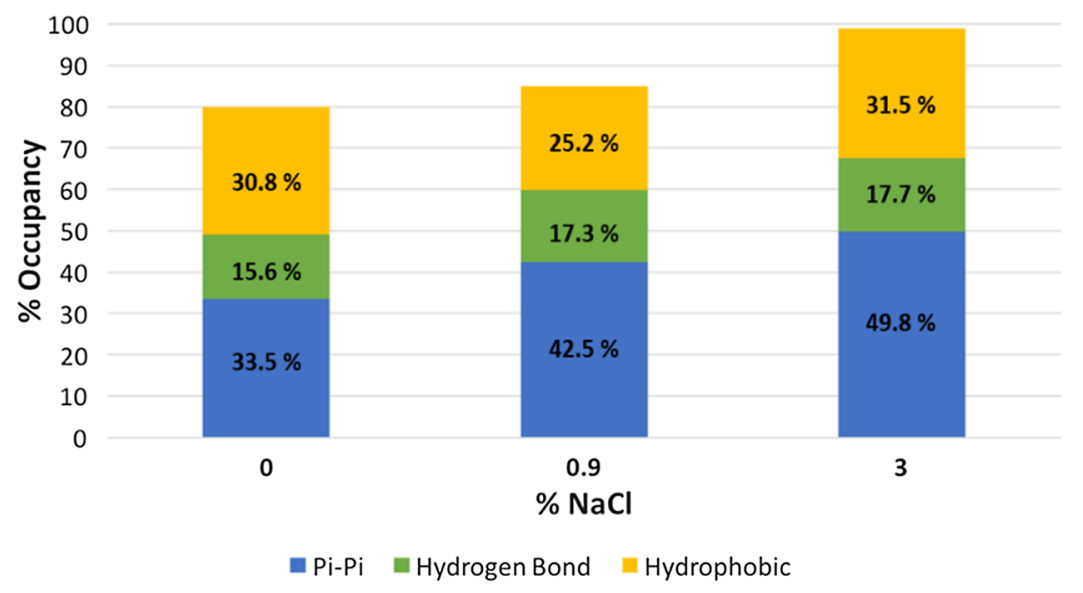

Fig. 4 a $\pi-\pi$, b hydrogen bond and, $\mathbf{c}$ hydrophobic interactions between PES and EE2 (\%), $\mathbf{d}$ simulated lifetime occupancies contributions of $\pi-\pi$ interactions, hydrogen bonding and hydrophobic interactions towards overall PES-EE2 interaction in various salinities 
this study. Although it is evident that the interaction between PES and EE2 is mainly contributed by physical interactions, the contribution of different forces in play (electrostatic, Van der Waals, hydrogen bonding, etc.) is unclear and there is insufficient information to explain the different adsorption capability or affinity of PES membrane with different types of hormones as found in a previous study ( $\mathrm{Ng}$ and Cao 2015). To probe into the types of intermolecular interactions observed between EE2 and PES and determine the effect of salinity on these interactions, molecular dynamics (MD) simulations of different salinity (i.e. salt concentration) were conducted.

Analysis of the simulations revealed three types of intermolecular interactions (Fig. 4). The $\pi-\pi$ interaction is defined as the interaction between the aromatic rings of the PES and EE2 molecules (Fig. 4a). Hydrogen bonding is defined as the interaction between the $\mathrm{SO}_{2}$ group of PES and the hydroxyl groups of EE2 (Fig. 4b). The hydrophobic interaction is defined as the interaction between the saturated fused rings of EE2 and the aromatic rings of PES (Fig. 4c). Regardless of the salt concentration, the $\pi-\pi$ interaction has the longest lifetime occupancy, followed by hydrophobic interaction and hydrogen bonding. Therefore, it is evident that the $\pi-\pi$ interaction accounts majorly for the retention of EE2 on PES (Fig. 4d).

The simulation model used in our study fits our experimental results well in general. We observed from our simulation that the increase in salt concentration also resulted in an increase in lifetime occupancy for each of the intermolecular interaction (with a single exception for the case of hydrophobic interaction from 0 to $0.9 \% \mathrm{NaCl}$ concentration). The addition of salt increases the ionic character of the solvent which decreases the energetic advantageousness of its interaction with hydrophobic PES and EE2 molecules (Fig. 4d).

Three main types of intermolecular interactions are observed between PES and EE2 in the MD simulations. Among them, $\pi-\pi$ interaction possesses the highest lifetime occupancy and thus is the major contributor towards strong interaction between PES and EE2. This is followed by hydrogen bonding and hydrophobic interaction. Our result is consistent with other studies which attribute $\pi-\pi$ interaction and hydrogen bonding as main interactions in adsorption-based removal of hormonal contaminants (Bope et al. 2018; Joseph et al. 2011; Han et al. 2013b). Therefore, future functionalisation of the polymeric membrane adsorbents can take advantage of these observed intermolecular interactions to include aromatic and hydrogen bond moieties for better retention of EE2 and other hormonal contaminants. On the other hand, increasing the salt concentration increases the ionic strength of the solvent environment, which is favourable for PES-EE2 interaction. Incorporating this information during design of specialised treatment facilities (in farming, pharmaceutical industries, etc.) can provide a more favourable condition for better retention of EE2 by the PES membrane. One potential application of this study is the development of membrane technology to remove synthetic hormones in farming wastewater prior to its release into the environment. Synthetic hormones are routinely used to improve the growth and reproduction of farmed animals (Verderame et al. 2016; Liu et al. 2012), and pre-treatment of farming wastewater via membrane adsorption can alleviate the problem of synthetic hormones contaminating the surrounding waterways and aquifers. Also, we recommend the inclusion of salinity as a factor in modelling the adsorption capacity of membranes to prevent the oversaturation of membrane and minimise the release of contaminants into the environment. Last but not least, our work provides fundamental but valuable insights to enable future studies on the physical interactions in complex systems, such as a biofilm membrane bioreactor which involves contaminants, membrane and microorganisms, towards more efficient and sustainable remediation processes.

\section{Conclusion}

This work investigates the effects of salinity on the adsorption of EE2 by PES membrane. The results indicate that influents with higher salinities improve retention EE2 onto PES membrane up to $98.7 \%$. This finding was supported by batch sorption studies of EE2 by comparing Freundlich parameters at different salinities where $n$ and $K_{\mathrm{f}}$ yielded the highest values at $3 \%$ salinity. Sorption studies further revealed that Freundlich isotherm fits better than Langmuir for the experimental data and can be reasonably used to model the adsorption of EE2 onto PES membrane. The relationship between salinity and adsorption of EE2 onto PES was further confirmed by the molecular simulation results which suggest that ionic strength of influent promotes the PES-EE2 interaction, allowing better retention of EE2 by the PES membrane at higher salinities. Also, three major types of intermolecular interactions are observed between PES and EE2 in the MD simulations. Among them, $\pi-\pi$ interaction is the strongest interaction because it possesses the highest lifetime occupancy. Therefore, future functionalisation of the PES membrane can take advantage of these observed intermolecular interactions for better retention of EE2. This study provides valuable information for improving treatment plant design to allow better removal of EE2 and other low-polar organic contaminants via the sorptionelution method. We recommend the inclusion of salinity as a factor in modelling the adsorption capacity of membranes to prevent the oversaturation of membrane and minimise the release of contaminants into the environment. 
Acknowledgements The authors thank Prof. Bin Cao of Nanyang Technological University, Singapore, for the useful discussions and suggestions throughout the project. CKN acknowledges Commonwealth Scholarship Commission for financial support in the form of Commonwealth Rutherford Fellowship (SGRF-2017-471).

\section{Declarations}

Conflict of interest The authors declare that they have no conflict of interest.

Open Access This article is licensed under a Creative Commons Attribution 4.0 International License, which permits use, sharing, adaptation, distribution and reproduction in any medium or format, as long as you give appropriate credit to the original author(s) and the source, provide a link to the Creative Commons licence, and indicate if changes were made. The images or other third party material in this article are included in the article's Creative Commons licence, unless indicated otherwise in a credit line to the material. If material is not included in the article's Creative Commons licence and your intended use is not permitted by statutory regulation or exceeds the permitted use, you will need to obtain permission directly from the copyright holder. To view a copy of this licence, visit http://creativecommons.org/licenses/by/4.0/.

\section{References}

Andersen HR, Hansen M, Kjølholt J, Stuer-Lauridsen F, Ternes T, Halling-Sørensen B (2005) Assessment of the importance of sorption for steroid estrogens removal during activated sludge treatment. Chemosphere 61:139-146

Aris AZ, Shamsuddin AS, Praveena SM (2014) Occurrence of $17 \alpha$-ethynylestradiol (EE2) in the environment and effect on exposed biota: a review. Environ Int 69:104-119

Ávila C, Bayona JM, Martín I, Salas JJ, García J (2015) Emerging organic contaminant removal in a full-scale hybrid constructed wetland system for wastewater treatment and reuse. Ecol Eng 80:108-116

Berendsen HJ, Postma JP, van Gunsteren WF, Hermans J (1981) Interaction models for water in relation to protein hydration. In: Intermolecular forces, Springer, 1981, pp 331-342

Bope CD, Nalaparaju A, Ng CK, Cheng Y, Lu L (2018) Molecular simulation on the interaction of Ethinylestradiol (EE2) with polymer membranes in wastewater purification. Mol Simul 40:1-10

Case DA, Cheatham TE III, Darden T, Gohlke H, Luo R, Merz KM Jr, Onufriev A, Simmerling C, Wang B, Woods RJ (2005) The Amber biomolecular simulation programs. J Comput Chem 26:1668-1688

Chen X (2015) Modeling of experimental adsorption isotherm data. Information 6:14-22

Chimchirian RF, Suri RP, Fu H (2007) Free synthetic and natural estrogen hormones in influent and effluent of three municipal wastewater treatment plants. Water Environ Res 79:969-974

Chung H-K, Kim W-H, Park J, Cho J, Jeong T-Y, Park P-K (2015) Application of Langmuir and Freundlich isotherms to predict adsorbate removal efficiency or required amount of adsorbent. $\mathrm{J}$ Ind Eng Chem 28:241-246

Crittenden JC, Trussell RR, Hand DW, Howe KJ, Tchobanoglous G (2012) MWH's water treatment: principles and design. Wiley, Hoboken

Darden T, York D, Pedersen L (1993) Particle mesh Ewald: an N. $\log (\mathrm{N})$ method for Ewald sums. J Chem Phys 98:10089-10092
De Rudder J, Van de Wiele T, Dhooge W, Comhaire F, Verstraete W (2004) Advanced water treatment with manganese oxide for the removal of 17 $\alpha$-ethynylestradiol (EE2). Water Res 38:184-192

Debye P (1909) Näherungsformeln für die Zylinderfunktionen für große Werte des Arguments und unbeschränkt veränderliche Werte des Index. Math Ann 67:535-558

Delle Site A (2001) Factors affecting sorption of organic compounds in natural sorbent/water systems and sorption coefficients for selected pollutants. A review. J Phys Chem Ref Data 30:187-439

Essmann U, Perera L, Berkowitz ML, Darden T, Lee H, Pedersen L (1995) A smooth particle mesh Ewald method. J Chem Phys 103:8577-8593

Febrianto J, Kosasih AN, Sunarso J, Ju Y-H, Indraswati N, Ismadji S (2009) Equilibrium and kinetic studies in adsorption of heavy metals using biosorbent: a summary of recent studies. J Hazard Mater 162:616-645

Fernandes AN, Giovanela M, Almeida CA, Esteves VI, Sierra M, Grassi MT (2011) Removal of the hormones 17 $\beta$-estradiol and $17 \alpha$-ethinylestradiol from aqueous solutions employing a decomposed peat as adsorbent material. Quím Nova 34:1526-1533

Giles C, MacEwan T, Nakhwa S, Smith D (1960) A system of classification of solution adsorption isotherms, and its use in diagnosis of adsorption mechanisms and in measurement of specific surface areas of solids. J Chem Soc 111:3973-3993

Gmurek M, Olak-Kucharczyk M, Ledakowicz S (2017) Photochemical decomposition of endocrine disrupting compounds-a review. Chem Eng J 310(Part 2):437-456

Han J, Qiu W, Hu J, Gao W (2012) Chemisorption of estrone in nylon microfiltration membranes: adsorption mechanism and potential use for estrone removal from water. Water Res 46:873-881

Han J, Meng S, Dong Y, Hu J, Gao W (2013a) Capturing hormones and bisphenol a from water via sustained hydrogen bond driven sorption in polyamide microfiltration membranes. Water Res 47:197-208

Han J, Qiu W, Cao Z, Hu J, Gao W (2013b) Adsorption of ethinylestradiol (EE2) on polyamide 612: molecular modeling and effects of water chemistry. Water Res 47:2273-2284

Hornak V, Abel R, Okur A, Strockbine B, Roitberg A, Simmerling C (2006) Comparison of multiple Amber force fields and development of improved protein backbone parameters. Proteins: Struct Funct Bioinf 65:712-725

Hsu B-M, Huang C (2002) Influence of ionic strength and $\mathrm{pH}$ on hydrophobicity and zeta potential of Giardia and Cryptosporidium. Colloids Surface A 201:201-206

Hu JY, Jin X, Ong SL (2007) Rejection of estrone by nanofiltration: Influence of solution chemistry. J Membrane Sci 302:188-196

Ivashechkin P, Corvini P-X, Dohmann M (2004) Behaviour of endocrine disrupting chemicals during the treatment of municipal sewage sludge. Water Sci Technol 50:133-140

Jakalian A, Jack DB, Bayly CI (2002) Fast, efficient generation of high-quality atomic charges. AM1-BCC model: II. Parameterization and validation. J Comput Chem 23:1623-1641

Joseph L, Zaib Q, Khan IA, Berge ND, Park Y-G, Saleh NB, Yoon Y (2011) Removal of bisphenol A and $17 \alpha$-ethinyl estradiol from landfill leachate using single-walled carbon nanotubes. Water Res 45:4056-4068

Liu S, Ying G-G, Zhang R-Q, Zhou L-J, Lai H-J, Chen Z-F (2012) Fate and occurrence of steroids in swine and dairy cattle farms with different farming scales and wastes disposal systems. Environ Pollut 170:190-201

Lyko S, Wintgens T, Melin T (2005) Estrogenic trace contaminants in wastewater-possibilities of membrane bioreactor technology. Desalination 178:95-105

Ma W, Sun J, Li Y, Lun X, Shan D, Nie C, Liu M (2018) $17 \alpha$-Ethynylestradiol biodegradation in different river-based 
groundwater recharge modes with reclaimed water and degradation-associated community structure of bacteria and archaea. J Environ Sci 64:51-61

Machado FM, Bergmann CP, Fernandes TH, Lima EC, Royer B, Calvete T, Fagan SB (2011) Adsorption of reactive red M-2BE dye from water solutions by multi-walled carbon nanotubes and activated carbon. J Hazard Mater 192:1122-1131

Matamoros V, Rodríguez Y, Albaigés J (2016) A comparative assessment of intensive and extensive wastewater treatment technologies for removing emerging contaminants in small communities. Water Res 88:777-785

McKie R (2016) £30bn bill to purify water system after toxic impact of contraceptive pill. In: The Guardian

Nagpal NK, Meays CL (2016) Water quality guidelines for pharmaceutically-active compounds (PhACs): 17 $\alpha$-ethinylestradiol (EE2). In: Ministry of Environment, British Columbia

$\mathrm{Ng} \mathrm{CK}$, Cao B (2015) What exactly are you filtering out? Environ Sci Technol 49:5259-5260

Ng CK, Bope CD, Nalaparaju A, Cheng Y, Lu L, Wang R, Cao B (2017) Concentrating synthetic estrogen $17 \alpha$-ethinylestradiol using microporous polyethersulfone hollow fiber membranes: Experimental exploration and molecular simulation. Chem Eng J 314:80-87

Pearlman DA, Case DA, Caldwell JW, Ross WS, Cheatham TE III, DeBolt S, Ferguson D, Seibel G, Kollman P (1995) AMBER, a package of computer programs for applying molecular mechanics, normal mode analysis, molecular dynamics and free energy calculations to simulate the structural and energetic properties of molecules. Comput Phys Commun 91:1-41

Perdrew JP, Wang Y (1992) Accurate and simple analytic representation of the electron-gas correlation energy. J Phys Chem B 45:13244-13249

Ren Y-X, Nakano K, Nomura M, Chiba N, Nishimura O (2007) A thermodynamic analysis on adsorption of estrogens in activated sludge process. Water Res 41:2341-2348

Rodríguez-Gómez R, Martín J, Zafra-Gómez A, Alonso E, Vílchez JL, Navalón A (2017) Biomonitoring of 21 endocrine disrupting chemicals in human hair samples using ultra-high performance liquid chromatography-tandem mass spectrometry. Chemosphere 168:676-684

Roe DR, Cheatham TE III (2013) PTRAJ and CPPTRAJ: software for processing and analysis of molecular dynamics trajectory data. $\mathrm{J}$ Chem Theory Comput 9:3084-3095

Rovani S, Censi MT, Pedrotti SL Jr, Lima ÉC, Cataluña R, Fernandes AN (2014) Development of a new adsorbent from agro-industrial waste and its potential use in endocrine disruptor compound removal. J Hazard Mater 271:311-320
Ryckaert J-P, Ciccotti G, Berendsen HJ (1977) Numerical integration of the cartesian equations of motion of a system with constraints: molecular dynamics of n-alkanes. J Comput Phys 23:327-341

Schäfer AI, Akanyeti I, Semião AJC (2011) Micropollutant sorption to membrane polymers: a review of mechanisms for estrogens. Adv Colloid Interfac 164:100-117

Schwarzenbach RP, Gschwend PM, Imboden DM (2005) Sorption I: general introduction and sorption processes involving organic matter. In: Environmental organic chemistry, Wiley, Hoboken, pp 275-330

Silva CP, Otero M, Esteves V (2012) Processes for the elimination of estrogenic steroid hormones from water: a review. Environ Pollut 165:38-58

Sinnokrot MO, Sherrill CD (2004) Highly accurate coupled cluster potential energy curves for the benzene dimer: sandwich, T-shaped, and parallel-displaced configurations. J Phys Chem A 108:10200-10207

Solé A, Matamoros V (2016) Removal of endocrine disrupting compounds from wastewater by microalgae co-immobilized in alginate beads. Chemosphere 164:516-523

Sumpter JP (2010) Pharmaceuticals in the environment: moving from a problem to a solution. in: Green and sustainable pharmacy, Springer, Berlin, pp 11-22.

Tomšíková H, Aufartová J, Solich P, Nováková L, Sosa-Ferrera Z, Santana-Rodríguez JJ (2012) High-sensitivity analysis of femalesteroid hormones in environmental samples. TRAC-Trend Anal Chem 34:35-58

Uberuaga BP, Anghel M, Voter AF (2004) Synchronization of trajectories in canonical molecular-dynamics simulations: Observation, explanation, and exploitation. J Chem Phys 120:6363-6374

Valix M, Cheung WH, McKay G (2004) Preparation of activated carbon using low temperature carbonisation and physical activation of high ash raw bagasse for acid dye adsorption. Chemosphere 56:493-501

Verderame M, Limatola E, Scudiero R (2016) Estrogenic contamination by manure fertilizer in organic farming: a case study with the lizard Podarcis sicula. Ecotoxicology 25:105-114

Wang J, Wang W, Kollman PA, Case DA (2006) Automatic atom type and bond type perception in molecular mechanical calculations. J Mol Graph Model 25:247-260

Wise A, O'Brien K, Woodruff T (2011) Are oral contraceptives a significant contributor to the estrogenicity of drinking water? Environ Sci Technol 45:51-60

Zimmermann K (1991) ORAL: all purpose molecular mechanics simulator and energy minimizer. J Comput Chem 12:310-319 